\title{
Educar para la Democracia
}

\section{Educate for democracy}

\author{
Marta Bueno Salinas \\ Profesora Titular de Historia del Derecho \\ Departamento de Historia del Derecho, Derecho Romano y Derecho Eclesiástico del Estado \\ Facultad de Derecho. \\ Universidad de Barcelona \\ E-mail: martabueno@ub.edu
}

\begin{abstract}
Resumen: El avance del Neoliberalismo (impulsor de un individualismo a ultranza) incide negativamente en las sociedades democráticas al desestabilizarlas aprovechando la progresiva pérdida de valores compartidos. Frente a ello, se defiende la vuelta a una educación que apueste en todos los niveles educativos por las humanidades como base para la formación de ciudadanos libres. Concretamente, la última reforma universitaria española, aunque empezó a esbozarlo, perdió la oportunidad de avanzarse a la meta $7^{\mathrm{a}}$ del objetivo 4 de los Objetivos de Desarrollo Sostenible - Agenda 2030.

Palabras clave: democracia, educación, valores, ética, ODS.
\end{abstract}

\begin{abstract}
The advance of Neoliberalism (current of political thought based on ultraindividualism) has a negative effect on modern democratic societies by destabilizing them as it takes advantage on the progressive loss of shared moral values. Faced with this, the return to an education that bets on all levels of education for the humanities as the basis for the formation of free citizens is defended. Although the last reform of the Spanish higher education system began to outline a plan in this sense, missed the opportunity to advance to 7 of Goal 4 of the Sustainable Development Goals - Agenda 2030.
\end{abstract}

Keywords: democracy, education, values, ethics, ODS. 


\section{Educar para la Democracia}

\section{Educate for democracy}

\section{Una sociedad democrática requiere compartir valores}

Como recuerda Harari, "[h]ace diez mil años la humanidad estaba dividida en incontables tribus aisladas. Con cada milenio que pasaba, estas tribus se fusionaron en grupos cada vez mayores, creando cada vez menos civilizaciones diferentes. En las generaciones recientes, las pocas civilizaciones que perduraban han estado uniéndose en una única civilización global. Las divisiones políticas, étnicas, culturales y económicas resisten, pero no socavan la unidad fundamental." (HARARI, 2018, 121). En este sentido, se habla de un único paradigma político, de una política global fundamentada en torno a tres grandes conceptos: respeto de los derechos humanos, consolidación de la soberanía estatal y acatamiento de la ley internacional. (HARARI, 2018, 123 y ss.).

La defensa de la existencia de un único paradigma político llevó en su momento a Fukuyama a plantear el fin de la Historia, por haberse dado "el último paso de la evolución ideológica de la humanidad y de la universalización de la democracia liberal occidental, como forma final de gobierno humano". (FUKUYAMA, 1990). A pesar de todas las críticas entonces recibidas, la evolución de los acontecimientos históricos acaecidos tras la caída del muro de Berlín, reflejo ésta del fracaso del Comunismo, y la entrada en el mercado mundial de una potencia como China (con adopción de los principios de libre mercado), lleva a cuestionarnos si finalmente tendremos que darle la razón a Fukuyama...

En cualquier caso, nos encontramos con un problema. Aunque aceptáramos el triunfo de un paradigma político, incluso aunque no negáramos la hegemonía del libre mercado, ambos presupuestos y/o consecuencias de la llamada 'globalización', no existe una única sociedad, una única comunidad universal, como tampoco existen culturas compactas. Tampoco la ética es, consecuentemente, uniforme. Asistimos a lo que Magris ha calificado como "politeísmo de valores" (MAGRIS, 2008) ${ }^{1}$, fragmentándose éstos ya no en tantas posibles sociedades que de manera más o menos artificiosa, jurídica o políticamente podamos delimitar, sino en todos y cada uno de los individuos que componen dichas sociedades. En otras palabras, las sociedades actuales parecen

\footnotetext{
${ }^{1}$ En cualquier caso, la expresión "politeísmo de valores" se debe a Max Weber. Vid. JIMÉNEZ-DÍAZ (2017) 105 .
} 
articularse a partir de los sentimientos y preferencias individuales. Para MacIntyre, ello es reflejo del emotivismo o subjetivismo imperante (MACINTYRE, 2001, 31 y ss.), estrechamente relacionado con los planteamientos individualistas de las corrientes neoliberales.

\section{De cómo el Neoliberalismo sustituye a la sociedad por el mercado de} individuos

Es conocido que en las décadas 50 y 60 los primeros pasos hacia la globalización hicieron avanzar la agenda socialdemócrata. La crisis de las materias primas y, concretamente en 1972, del petróleo provocaron que en las décadas siguientes (años 70 y 80) se cuestionaran las políticas keynesianas sobre las que se había ido construyendo, con distintos modelos, el Estado del Bienestar. ${ }^{2}$ Los planteamientos socialdemócratas parecieron tambalearse en todos los ámbitos: escolar, laboral, familiar... Ello facilitó la vuelta a posturas liberales a partir del movimiento llamado Neoliberalismo, corriente que tuvo en Friedrich A. Hayek a su paladín. (URRUTIA, 2016). Las reflexiones del pensador austríaco se encaminaron a construir una teoría social coherente. Desde su perspectiva, a partir del Renacimiento el hombre individual se erige como protagonista indiscutible de la civilización, de manera paralela a cómo se fue consolidando de forma espontánea el orden del mercado.

Para Hayek, el mercado se ha desvelado como el sistema más eficaz para garantizar el desarrollo individual. De hecho, el colectivo social es una mera abstracción, sin “existencia y realidad más allá de las acciones individuales.” (URRUTIA, 2016, 1232). La sociedad, por tanto, no existe. ${ }^{3}$ Lo que existe es el intercambio individual, esto es, el mercado.

Efectivamente, como concluye Urrutia, "[1]la sociedad, en el pensamiento de Hayek, no es vista sino como un medio para la consecución de los fines individuales y su génesis obedece a una necesidad de tipo económico. Se reduce a relaciones de intercambio." (URRUTIA, 2016, 1233).

\footnotetext{
${ }^{2}$ Los modelos teorizados del Estado del Bienestar son cuatro: el liberal o anglosajón, el continental corporativista, el familiar mediterráneo y el nórdico socialdemócrata.

${ }^{3}$ Esta idea fue recogida por Margaret Thatcher quien, en entrevista de la revista Woman's Own, publicada el 31 de octubre de 1987, afirmaría: "La sociedad no existe; [...] hay individuos, hombres y mujeres". Disponible en https://www.margaretthatcher.org/document/106689
} 
A partir de estas premisas, "[e]l papel de la política no debe consistir en tratar de obtener objetivos concretos, o perseguir fines comunes, sino en la formación y mantenimiento de ese orden global abstracto que haga posible que cada uno alcance sus fines particulares." (URRUTIA, 2016, 1227). La intervención del Estado, el papel de la política queda reducido, así, a su mínima expresión.

Ahora bien, no se trata ahora de analizar la relación Estado/mercado, como destacar la consecuencia que deriva de la negación hayekiana de la sociedad, en la medida en que llevaría a negar, a su vez, lo político. Efectivamente, para Hayek, no debería haber más política que aquella tendente a asegurar las condiciones del libre mercado, es decir, la autorregulación del mercado. ${ }^{4}$ Hayek defiende la aparición de sociedades abiertas a partir de la Modernidad. Éstas, a diferencia de las comunidades sociales de fines anteriores, no requieren de unidad moral. Su orden es espontáneo, fruto de la convergencia de intereses individuales. En este contexto, apuesta por la demarquía como régimen político, esto es un "orden institucional cuyo principal objetivo es expulsar la política de la polis, cerrándole todas las vías de acceso posibles. [...] [T]odo está orientado a impedir que haya cualquier tipo de contaminación política en la configuración del orden espontáneo.” (MANSUY, 2015, 53). ${ }^{5}$

En definitiva, la falta de unidad moral de las sociedades actuales erige a los sentimientos y preferencias -que no valores- individuales en sustitutos de normas morales objetivas, cohesionadoras de los grupos sociales. En este contexto, los desacuerdos morales son irresolubles. ${ }^{6}$

Llegados a este punto, y sintiéndonos más próximos a las corrientes social-demócratas que neoliberales, podemos reflexionar con Judt: “¿qué tipo de sociedad queremos y qué clase de acuerdos estamos dispuestos a tolerar para instaurarla?”. (JUDT, 2017, 219). En eso debería centrarse el hacer política. Y, como el propio Judt se encarga de recordarnos, no puede hacerse política "ignorando las consideraciones éticas y toda referencia a unos objetivos sociales más amplios”. (JUDT, 2017, 220).

\footnotetext{
${ }^{4}$ MANSUY (2015) 48: "[E]l esfuerzo de Hayek parece dirigido a mostrar que lo económico se despliega con independencia del cuadro político, y que la economía es un fenómeno que no necesita de contexto político, más allá de las reglas abstractas."

${ }^{5}$ De 'idelología antipolítica' habla INNERARITY (2017) 79.

${ }^{6}$ Vid. LOIRA (2017) 31-41.
} 


\section{Seamos virtuosos antes que emotivistas.}

No todo está perdido. La democracia liberal se sustenta en "cinco principios irrenunciables", como los califica Otfried Höffe:

1. respeto a las reglas (esto es, al Derecho), frente a la arbitrariedad privada;

2. poderes públicos -en lugar de justicia privada- para la determinación de dichas reglas;

3. estos poderes han de surgir de la propia ciudadanía;

4. dichos poderes han de separarse para impedir el abuso de poder;

5. y, por último, las reglas han de respetar los derechos humanos, identificados como máximas de la moral del Derecho. (HÖFFE, 2007, 89 y ss.)

Ahora bien, dichos principios requieren de una ciudadanía educada activamente en los mismos, es decir, de una ciudadanía virtuosa, en tanto que conocedora, del sentido del Derecho, del sentido de la Justicia y del sentido Comunitario. En el fondo, requiere de una ciudadanía educada en valores compartidos. (HÖFFE, 2007, 161 y ss.). ${ }^{7}$

¿Qué valores son -o deberían ser- éstos? En un análisis histórico, Höffe destaca lo que identifica como siete puntos culminantes (HÖFFE, 2007, 151 y ss.):

$1^{\circ}$. En la tradición de la Europa occidental, el momento del mito identifica el primer punto culminante. En esta etapa los valores primordiales se reflejan en dioses, dotándoles así de "una validez suprapositiva, ajena a la arbitrariedad de las personas". (HÖFFE, 2007, 152). La moral, la justicia, la paz facilitadora de prosperidad económica y cultural están representados por las diosas Eunomia, Diké y Eirene.

$2^{\circ}$. Desde una perspectiva más global, el segundo punto culminante rastrea los valores de la India, China, Egipto e Israel antiguos. Aparecen los ya mencionados en el apartado anterior, así como el de la reciprocidad y la igualdad, entre otros.

$3^{\circ}$. Aristóteles encarna el tercer punto culminante. En la introducción a su obra Política concreta los pilares de una polis: la reciprocidad y la justicia, valor éste al que dedica el libro V de la Ética a Nicómaco. Aristóteles también destaca el papel de la equidad, así como el de la amistad.

\footnotetext{
${ }^{7}$ Siendo muchísimas la bibliografía que podría citarse, léase el interesante JUDT (2017) 176 y ss.
} 
$4^{\circ}$. El cuarto momento o punto culminante nos lleva a Hobbes. Para él el valor sobresaliente es la paz, a cuya consecución debe dirigirse el Derecho y el Estado como titular de la fuerza.

$5^{\circ}$. Quinto momento y central es Kant. Erige al Derecho en valor fundamental, diferenciado de la Justicia, representando ésta un criterio moral. Por su parte, la Justicia está en la base del valor absoluto de cada persona, esto es, de la dignidad humana. Se da un cambio significativo porque ya no preocupa tanto cómo proteger a la sociedad sino cómo ésta protege al individuo.

$6^{\circ}$. En el sexto punto culminante Höffe esgrime la defensa por Émile Durkheim de la solidaridad como valor vertebrador de la cohesión social. Según el sociólogo, la solidaridad orgánica de las primeras sociedades dio paso, a partir de la configuración conceptual del individuo, a una solidaridad mecánica, articulada a través del Derecho (y ya no de la amistad o fraternidad).

$7^{\circ}$. En el séptimo y último punto culminante respecto de los valores que cohesionan una sociedad, John Rawls destaca nuevamente a la Justicia: "una sociedad -afirmase basa fundamentalmente en la amistad y en la confianza de los ciudadanos, en los principios de justicia comunes. Y en la actitud, convertida ya en atributo de la personalidad, de vivir de manera acorde.” (HÖFFE, 2007, 157).

Johns Rawls plantea valores que pretende universales. En esa misma línea se encuadran loables proyectos, como la Declaración Universal de Derechos Humanos, aprobada en 1948, cual "ideal común para todos los pueblos y naciones."8 Pero, para alcanzar estos innegables ideales creemos que debería superarse el subjetivismo que impera en las sociedades democráticas. En este sentido, la crítica al emotivismo y el planteamiento de MacIntyre en defensa de la corriente tildada de comunitarista me parece acertada. ${ }^{9}$

Para MacIntyre, y como señala Saiz, "la moral no existe nunca en abstracto, ahistóricamente, sino que siempre se encarna en prácticas sociales apoyadas sobre significados, creencias y principios compartidos y, a través de esas prácticas concretas,

\footnotetext{
${ }^{8}$ http://www.un.org/es/universal-declaration-human-rights/

Cfr. la interesante reflexión de NUSSBAUM (2005) 180 y ss., concluyendo: "la historia de los derechos humanos sugiere que una actitud desdeñosa hacia las culturas no occidentales se basa, por lo menos en algún grado, en un chovinismo normativo sin fundamento." (186).

${ }^{9}$ Vid. MACINTYRE (1994), muy interesante y sugerente.
} 
se adquieren y desarrollan las virtudes." (SAIZ, 2015, 311). La cohesión social requiere de valores comunes. $\mathrm{Y}$ éstos solo son alcanzables en sociedades cuyos miembros comparten tradiciones, cultura, historia. ¿Quiere ello decir que no podemos deducir de las democracias liberales unos valores comunes? No, los hay. ${ }^{10}$ Pero, porque estas democracias, las sociedades que las componen, comparten elementos estructurales que, a su vez, descansan en determinados valores. El problema surge cuando desde esas mismas democracias se cuestiona el significado de los valores compartidos.

En todo caso, y siguiendo el planteamiento de MacIntyre o del mismo Judt, no basta con identificar valores comunes a los distintos grupos sociales; la sociedad ha de reencontrar su sentido como comunidad y -como ya hemos señalado anteriormente- reeducarse en aquellos valores que precisamente la justifican. Solo así estaremos en condiciones de superar la calificada como "crisis del sistema de vida occidental."11

\section{Educar en valores... Un caso concreto: España}

Nuestra palabra 'ética' procede de la griega ethikós. Isidoro de Sevilla testimonia en sus Etimologías, al hablar de la Filosofía, cómo esta palabra fue traducida al latín por moralis. ${ }^{12}$ Parece que debemos a Cicerón dicha traducción al utilizarla por vez primera en su obra De Fato ${ }^{13}$, según nos explica MacIntyre, quien precisa su significado como "«perteneciente al carácter» y el carácter de un hombre no es otra cosa que el conjunto de las disposiciones que sistemáticamente le llevan a actuar de un modo antes que de otro, a llevar una determinada clase de vida." (MACINTYRE, 2001, 71). ${ }^{14}$ La idea de ética o moral originariamente queda vinculada, por tanto, al carácter de cada uno y a las actuaciones que van jalonando nuestras vidas. Carácter, conducta... la ética o moral alude en definitiva al comportamiento de los individuos al manifestarse en el actuar de los mismos. Dicho comportamiento se valora respecto de la ética dominante en el grupo social al que pertenecemos. Y ello porque vivimos en comunidad. Pensarnos fuera de ella

\footnotetext{
${ }^{10}$ Vid. HÖFFE (2007) 157 y ss. El A. distingue valores de índole económica; político-sociales; personales en cuanto que individuos; de cohesión social (como la lengua, la ciencia o la filosofía, la fraternidad, etc.); universales. De los mismos se erige como rector un sentido de justicia mundial.

${ }^{11}$ Vid. SAMPREDO (2011) 15-23, citado por GUICHOT-REINA (2015) 48.

12 Etimologías II, 24, 3: “[...] Philosophiae species tripertita est: una naturalis, quae Graece Physica appelatur [...]; altera moralis, quae Graece Ehtica dicitur, in qua de moribus agitur [...]"

${ }^{13}$ De Fato I, 1: "[...] quia pertinet ad mores, quod ethos illi vocant, nos eam partem philosophiae de moribus appellare solemus, sed decet augentem linguam Latinam nominare morale." Disponible en http://www.thelatinlibrary.com/cicero/fato.shtml\#1

${ }^{14}$ Debe, no obstante, corregirse en la edición usada la referencia a la obra de Cicerón, identificada erróneamente como De tato.
} 
solo está al alcance de reflexiones literarias. Ciertamente, la afirmación aristotélica de ser el individuo un 'animal político' (zoon politikon) tiene todavía hoy pleno sentido. ${ }^{15}$ No podemos entendernos sin la dimensión social, dimensión que, junto a la palabra razonada (logos) nos caracteriza como especie. Somos animales sociales, esto es, políticos.

Un matiz importante: como ya señalaban los griegos, la acción del individuo depende en última instancia de su carácter, forjado éste con elementos que descansan en su temperamento y aquellos otros aprehendidos culturalmente. Biología y cultura, biología y educación intervienen, por tanto, en nuestra formación como seres humanos. ${ }^{16}$ Adentrémonos en la educación.

Bajo gobierno socialista, se aprobó en España la Ley Orgánica 2/2006, de 3 de mayo, de Educación (en adelante, LOE). ${ }^{17}$ En su preámbulo se especificaba que "ocupa un lugar relevante, en la relación de principios de la educación, la transmisión de aquellos valores que favorecen la libertad personal, la responsabilidad, la ciudadanía democrática, la solidaridad, la tolerancia, la igualdad, el respeto y la justicia, que constituyen la base de la vida en común." Desde esa perspectiva, se introdujo la materia "Educación para la Ciudadanía y los Derechos Humanos", encaminada a "ofrecer a todos los estudiantes un espacio de reflexión, análisis y estudio acerca de las características fundamentales y el funcionamiento de un régimen democrático, de los principios y derechos establecidos en la Constitución española y en los tratados y las declaraciones universales de los derechos humanos, así como de los valores comunes que constituyen el sustrato de la ciudadanía democrática en un contexto global." Con esta finalidad, la materia se introducía en las distintas etapas escolares a partir de asignaturas concretas. ${ }^{18}$

15 Vid. el interesante estudio antropológico GINTIS/VAN SCHAIK/BOEHM (2015). Los autores concluyen, ante el auge de la robótica y la posibilidad de que se haga realidad la novela 1984 de Orwell, que los seres humanos solo aceptan una jerarquía de dominación social coercitiva si los mecanismos coercitivos y los procesos sociales pueden legitimarse culturalmente. Esta legitimación se ha constatado difícil, salvo en los casos basados en el patriarcado, la religión o los principios de la democracia liberal.

Ha de tenerse en cuenta el matiz que introduce ARENDT (1997) 46: "La política nace en el Entre-loshombres".

\footnotetext{
${ }^{16}$ Vid. MARINA/RAMBAUD (2018) 14: "La evolución biológica dejó a nuestra especie en la playa de la historia. Apareció entonces un extraño híbrido, mezcla de biología y cultura, inquieto y sometido a permanente cambio. Nuestra naturaleza nos impulsa a crear cultura y, al hacerlo, nos recreamos. Una especie muda creó el lenguaje, y ahora no podemos pensar sin él. Unos seres preparados para vivir en pequeños grupos han creado sociedades extensas. Tenemos, por ello, un doble genoma: el biológico y el cultural. Aquel ha sido ya descifrado, y tal vez haya llegado el momento de descifrar el otro."

${ }^{17}$ https://www.boe.es/buscar/pdf/2006/BOE-A-2006-7899-consolidado.pdf

${ }^{18}$ Real Decreto (en adelante, RD) 1513/2006, de 7 de diciembre; RD 1631/2006, de 29 de diciembre; RD $1467 / 2007$, de 2 de noviembre.
} 
Pero, la pretensión de cumplir con las recomendaciones de las Naciones Unidas (a través de la UNESCO $)^{19}$ y del Consejo de Europa ${ }^{20}$ devino estéril con la llegada al poder del PP. La presión de las élites educativas conservadores consiguió eliminar aquella materia y provocar las reformas introducidas por la Ley Orgánica para la Mejora de la Calidad Educativa (en adelante, LOMCE) desde $2013 .{ }^{21}$ A partir de esta Ley, tal y como se recoge en el apartado XIV del Preámbulo, la Recomendación (2002)/12) quedaba conscientemente diluida en "todas las asignaturas durante la educación básica, de forma que la adquisición de competencias sociales y cívicas se incluya en la dinámica cotidiana de los procesos de enseñanza y aprendizaje [...]". Las generaciones futuras de la ciudadanía española perdieron, así, la oportunidad de profundizar en etapa escolar en el conocimiento de los valores democráticos. ${ }^{22}$

Pero, lo realmente significativo es que la LOMCE planteara como objetivos generales el introducir "nuevos patrones de conducta que ubiquen la educación en el centro de nuestra sociedad y economía." La referencia a la economía en posición clave junto a la sociedad refleja un ideario de corte neoliberal, alejado del ideario de la democracia social. De hecho, el Preámbulo invoca a la Organización para la Cooperación y Desarrollo Económicos (en adelante, OCDE) hasta en siete ocasiones. ${ }^{23}$ Por todo ello, no extraña que las primeras palabras con las que se inicia el Preámbulo refieran a los individuos a los que se dirige la educación, sin contemplar de manera directa o indirecta a la sociedad

\footnotetext{
${ }^{19}$ https://es.unesco.org/themes/ecm Vid., la reciente publicación sobre la necesidad de reforzar el Estado de Derecho a través de la educación: UNESCO (2019).
}

Vid., un año antes de la LO 2/2006, UNESCO (2006).

${ }^{20}$ RECOMENDACIÓN [Rec (2002) 12].

${ }^{21}$ Ley Orgánica 8/2013, de 9 de diciembre, para la mejora de la calidad educativa, disponible en https://www.boe.es/buscar/act.php?id=BOE-A-2013-12886

Como curiosidad, una mera comparación lingüística de los Preámbulos de ambas leyes refleja que mientras en la LOE el sustantivo más empleado fue 'educación' ( 88 veces. El segundo sustantivo, 'centros', 45 veces), en la LOMCE fue 'sistema' (45 veces. Por su parte, 'educación' es empleada 38 veces, así como 'educativo').

${ }^{22}$ Vid. MUÑOZ RAMÍREZ (2016). También, el interesante análisis histórico y la bibliografía citada en NAVAL/ARBUÉS (2016).

No obstante, con ocasión del compromiso adquirido por España en el Tercer Plan de Acción 2017-19 de la Alianza para el Gobierno Abierto, se han elaborado unas guías dirigidas a docentes y alumnos de Educación Primaria, Educación Secundaria y Bachillerato. Estas guías responden al proyecto de "fomentar en niños y jóvenes competencias sociales y cívicas para el ejercicio de una ciudadanía democrática, en la que se exija a las Administraciones Públicas transparencia y rendición de cuentas, y se ejerza una actitud responsable de colaboración y participación activa en los asuntos públicos", según consta en la página web http://transparencia.gob.es/transparencia/transparencia_Home/index/Gobiernoabierto/EduGobAbierto.html\#Componente0

${ }^{23}$ Vid. la crítica de la comunidad educativa hacia los informes de la OCDE en relación a la educación como "demasiados economicistas" en https://www.eldiario.es/sociedad/organizacion-economica-desarrolloOCDE-referente 0 304819994.html 
de la que forman parte: “[e]l alumnado es el centro y la razón de ser de la educación. El aprendizaje en la escuela debe ir dirigido a formar personas autónomas, críticas, con pensamiento propio. Todos los alumnos y alumnas tienen un sueño, todas las personas jóvenes tienen talento. Nuestras personas y sus talentos son lo más valioso que tenemos como país."

De manera muy distinta, la LOE había expresado claramente que "[p]ara la sociedad, la educación es el medio de transmitir y, al mismo tiempo, de renovar la cultura y el acervo de conocimientos y valores que la sustentan, de extraer las máximas posibilidades de sus fuentes de riqueza, de fomentar la convivencia democrática y el respeto a las diferencias individuales, de promover la solidaridad y evitar la discriminación, con el objetivo fundamental de lograr la necesaria cohesión social." A diferencia del Preámbulo analizado en el párrafo anterior, la LOE no hace referencia ni una sola vez a la OCDE. Y, sin desconocer a los jóvenes a los que la educación se dirige, ${ }^{24}$ el proyecto educativo socialista reconocía sin tapujos la finalidad última esperable de la educación: promover la cohesión social.

Un futuro de individuos, con clara apuesta por valores singulares, o un futuro de sociedades más cohesionadas a partir de valores compartidos. Uno y otro modelo están en la base de las leyes educativas referenciadas. ${ }^{25}$

\footnotetext{
24 "La educación es el medio más adecuado para construir su [de los jóvenes] personalidad, desarrollar al máximo sus capacidades, conformar su propia identidad personal y configurar su comprensión de la realidad, integrando la dimensión cognoscitiva, la afectiva y la axiológica."

${ }^{25}$ En el momento de finalizar este artículo el Gobierno en funciones de España tiene aprobado con fecha 15 de febrero de 2019 un Proyecto de Ley por el que se modifica la Ley Orgánica 2/2006, de 3 de mayo, de Educación. Entre los enfoques que describen el Proyecto destaca el cuarto: "reconoce la importancia de atender al desarrollo sostenible de acuerdo con lo establecido en la Agenda 2030. [Se refiere a los Objetivos de Desarrollo Sostenible aprobados por la ONU el 25 de septiembre del 2015 en el marco de la Agenda por el Desarrollo Sostenible. Vid. https://www.un.org/sustainabledevelopment/es/2015/09/la-asambleageneral-adopta-la-agenda-2030-para-el-desarrollo-sostenible/ y, especialmente, el Objetivo 4, Educación de calidad]. Así, la educación para el desarrollo sostenible y la ciudadanía mundial ha de incardinarse en los planes y programas educativos de la totalidad de la enseñanza obligatoria, incorporando los conocimientos, capacidades, valores y actitudes que necesitan todas las personas para vivir una vida fructífera, adoptar decisiones fundamentadas y asumir un papel activo - tanto en el ámbito local como mundial - a la hora de afrontar y resolver los problemas comunes a todos los ciudadanos del mundo. La educación para el desarrollo sostenible y para la ciudadanía mundial incluye la educación para la paz y los derechos humanos, la educación intercultural y la educación para la transición ecológica y la comprensión internacional." Bajo este enfoque se propone añadir "en el tercer ciclo un área de Educación en Valores cívicos y éticos, en la cual se prestará especial atención al conocimiento y respeto de los Derechos Humanos y de la Infancia, a los recogidos en la Constitución española, a la educación para el desarrollo sostenible y la ciudadanía mundial, a la igualdad entre hombres y mujeres y al valor del respeto a la diversidad, fomentando el espíritu crítico y la cultura de paz y no violencia." Puede verse en http://www.congreso.es/public_oficiales/L12/CONG/BOCG/A/BOCG-12-A-49-1.PDF
} 
Y ¿qué ocurre con las Universidades? ¿Deben éstas, más allá de la formación específica, técnica o humanística, aspirar a formar ciudadanos demócratas? Efectivamente, el 9 de octubre de 1998 se aprobaba en París la "Declaración mundial sobre la educación superior en el siglo XXI: visión y acción”. ${ }^{26}$ La letra e) del artículo primero establecía como misión de la educación superior "contribuir a proteger y consolidar los valores de la sociedad, velando por inculcar en los jóvenes los valores en que reposa la ciudadanía democrática y proporcionando perspectivas críticas y objetivas a fin de propiciar el debate sobre las opciones estratégicas y el fortalecimiento de enfoques humanistas." La reflexión sobre la necesidad de formar ciudadanos no dejaba al margen a los estudios universitarios. ${ }^{27}$

Todavía de manera muy incipiente, se defiende la conveniencia de "insertar temáticas relacionadas con Derechos Humanos, como cursos electivos o bien obligatorios según la realidad de cada disciplina, pero que sean ofrecidos de forma transversal para todas las carreras." (HENRIQUEZ, 2015, 63). En cualquier caso, no se trata solo de pivotar en torno a los derechos humanos una formación universitaria que se pretenda forjadora de ciudadanos. Ello podría quedar en mero papel mojado. Como señala Nussbaum, la educación actual utilitarista, en exceso técnica, ha de dejar paso nuevamente a una educación liberal en cuanto forjadora de hombre libres, a una educación humanista. Hemos de contribuir a formar ciudadanos mundiales. (NUSSBAUM, 2010 y 2005). Y, para ello, Nussbaum nos indica que es necesario cultivar la capacidad de autoexamen o vida examinada, la capacidad de saberse formando parte de una comunidad mundial y la capacidad de imaginar con compasión las dificultades de los otros. (NUSSBAUM, 2010, 26 y ss.).

La primera de las capacidades mencionadas fundamenta la formación de la persona en la apuesta por un conocimiento no basado en el principio de autoridad, sino en procesos de reflexión críticos, razonables, coherentes.

Y hemos de formarnos y formar sabedores de que nuestro destino está ineludiblemente unido al de los otros, sabedores de que somos cosmopolitas, ciudadanos del mundo.

\footnotetext{
${ }^{26}$ Disponible en https://unesdoc.unesco.org/ark:/48223/pf0000113878_spa

${ }^{27}$ Vid. HENRÍQUEZ R. (2015) y el atento análisis bibliográfico de CASTELLANOS CLARAMUNT (2019).
} 
La educación que propone Nussbaum aboga por una tercera dimensión: el respeto de los derechos humanos, en la base de todo sistema que se pretenda democrático, requiere ciudadanos compasivos, empáticos, sensibles ante el dolor de otros.

Este triple objetivo ha de estar presente en todo proceso educativo, tanto en los años escolares como en los universitarios. Centrándonos en éstos, la Universidad ha de promover la capacidad crítica de los estudiantes. Ésta ha de despertarse o mantenerse despierta, así como la capacidad deliberativa y de argumentación. Efectivamente ello solo es posible en grupos reducidos y con una docencia de tipo seminario y no magistral, en la medida en que no se trata de transmitir, sino de guiar en la adquisición de conocimientos. Esta docencia ha de promover los análisis multiculturales, facilitadores de la generación de conciencia global. Y ha de aprovechar la dimensión narrativa para acercar realidades de otra manera ocultas. La literatura, el cine, la pintura, las artes en generales facilitan hacer presente y comprender otras vidas. ${ }^{28}$

En España se desaprovechó la oportunidad de dotar de contenido humanístico en la línea descrita por Nussbaum la última reforma universitaria, aprobada por la Ley Orgánica de 12 de abril de $2007 .{ }^{29}$ Aunque en su preámbulo se recordaba "el papel de la universidad como transmisor esencial de valores" y concretaba "la creación de programas específicos sobre la igualdad de género, de ayuda a las víctimas del terrorismo y el impulso de políticas activas para garantizar la igualdad de oportunidades a las personas con discapacidad"; aunque reconociera expresamente que "[la] igualdad entre hombres y mujeres, los valores superiores de nuestra convivencia, el apoyo permanente a las personas con necesidades especiales, el fomento del valor del diálogo, de la paz y de la cooperación entre los pueblos, son valores que la universidad debe cuidar de manera especial”, no dotó a la educación universitaria de contenido específico en dichas materias.

La adaptación en general de los títulos de enseñanzas universitarias a los objetivos del Espacio Europeo de Educación Superior (en adelante, EEES) se perfiló -siguiendo las bases introducidas por LO 4/2007, de 12 de abril, acabada de mencionar- por el RD 1393/2007, de 29 de octubre. ${ }^{30}$ En el preámbulo de éste se preveía, de manera conclusiva que "se debe tener en cuenta que la formación en cualquier actividad profesional debe

\footnotetext{
${ }^{28}$ Vid. la aproximación a estas propuestas de Nussbaum en GUICHOT-REINA (2015) 58 y ss. Y el número 9 (2014) de la Revista de Educación y Derecho, dedicado a "Pedagogía, Cine, Literatura y Derecho".

${ }^{29} \mathrm{https}: / / \mathrm{www} \cdot$ boe.es/buscar/doc.php?id=BOE-A-2007-7786

30 https://www.boe.es/buscar/act.php?id=BOE-A-2007-18770
} 
contribuir al conocimiento y desarrollo de los Derechos Humanos, los principios democráticos, los principios de igualdad entre mujeres y hombres, de solidaridad, de protección medioambiental, de accesibilidad universal y diseño para todos, y de fomento de la cultura de la paz." Ello se concretaba en el apartado c) del párrafo 5 del artículo 3, al recoger entre los principios generales que debían estar presentes en el diseño de las nuevas titulaciones "los valores propios de una cultura de paz y de valores democráticos".

Si el legislador lo tenía claro, ¿por qué no se aprovechó para dotar de contenido efectivo aquel desideratum? De hecho, la reforma de los estudios universitarios nacía con la intención de introducir una formación básica de carácter transversal ${ }^{31}$ en la que hubieran podido encajarse materias comunes, haciendo efectivo lo manifestado por Nussbaum: "Es imposible que las instituciones terciarias y universitarias transmitan el tipo de enseñanza que hacen a un ciudadano del mundo si no cuentan con estructuras dedicadas a la educación humanística, es decir, con al menos un conjunto de cursos de formación general para todos los alumnos aparte de las materias obligatorias para cada carrera principal." (NUSSBAUM 2010, 129). Pero, como ya he señalado, la autonomía universitaria y, dentro de ésta, la de cada titulación, dio al traste con la transversalidad humanística que hubiera podido introducirse. Las titulaciones cubrieron el expediente a través de las 'competencias' generales y específicas, desplazando a cada asignatura el introducir la dimensión ética y confiando en que cada profesor en su aula encontraría la fórmula docente apropiada para transmitir esos valores. ${ }^{32}$

Tampoco debemos exagerar. Es cierto que el RD se mostraba solo tímidamente en la línea mencionada. En este sentido, si bien reconocía la conveniencia de primar la formación básica y generalista del estudiante, ${ }^{33}$ apostaba porque los créditos de formación básica se desplegarán en el seno de cada rama de conocimiento que el RD preveía, ${ }^{34}$ al fijar que un $60 \%$ de dicha formación se vinculara a materias integrantes de la misma rama. ${ }^{35} \mathrm{El} \mathrm{RD}$ no prescribía, por tanto, “cursos de formación general para todos los alumnos aparte de las materias obligatorias para cada carrera principal" en la línea que hemos visto formulada por Nussbaum. Es decir, eran las propias titulaciones integrantes de las distintas materias de cada rama de conocimiento las que podían compartir un número

\footnotetext{
31 Artículo 12.5.

${ }^{32}$ En este sentido, MARTINEZ (2006).

33 Artículo 12.1.

34 Arte y Humanidades, Ciencias, Ciencias de la Salud, Ciencias Sociales y Jurídicas e Ingeniería y Arquitectura.

${ }^{35}$ Artículo 12.4.
} 
mínimo de créditos calificados de formación básica. No obstante, el RD sí abría la posibilidad para el $40 \%$ restante de que dichos créditos básicos procederían de otras ramas de conocimiento, ya fuera por configurarse como asignaturas básicas para la concreta formación inicial o por su carácter transversal. En ese $40 \%$ se hubiera podido integrar una asignatura de contenido básico, generalista y de corte humanístico, dirigida a hacer presentes los valores democráticos para todos los estudiantes universitarios de unas $\mathrm{u}$ otras materias y ramas de conocimiento. El propio RD así lo permitía, aunque no le diera contenido de manera expresa. Al quedar tan abierto, no expresamente formulado y muchos menos desarrollado, se posibilitó la todavía actuación como auténticos gremios de las distintas áreas de conocimiento quienes reprodujeron en los nuevos planes de estudio de las diferentes titulaciones antiguas sinergias, desaprovechando así la oportunidad que apenas empezaba a insinuarse por el legislador.

En el caso concreto de los estudios de Derecho, es conocido que éstos dan nombre a la materia Derecho, integrada exclusivamente ${ }^{36}$ en el área de Ciencias Jurídicas y Sociales junto a otras once materias especificadas en el siguiente cuadro:

\begin{tabular}{|l|l|l|l|l|l|}
\hline Antropología & Ciencia Política & Comunicación & Derecho & Economía & Educación \\
\hline Empresa & Estadística & Geografía & Historia & Psicología & Sociología \\
\hline
\end{tabular}

Un análisis de la formación básica de las principales titulaciones de dichas materias en la Universidad de Barcelona refleja el siguiente panorama:

- En general se optó por rediseñar como contenidos de formación básica antiguas asignaturas de la propia titulación consideradas propedéuticas.

- La transversalidad conseguida fue mínima, normalmente limitada a asignaturas de titulaciones adscritas a la misma Facultad o que ya estuvieran presentes en las titulaciones que se reformaban.

- Salvo que la propia titulación ya estuviera dotada de asignaturas relacionadas con los valores democráticos (como es el caso de Derecho), no se diseñó una asignatura ad hoc, de carácter transversal, para todas las titulaciones del área de conocimiento.

\footnotetext{
${ }^{36}$ Las materias pueden integrar una o más áreas de conocimiento, como quedó recogido en el Anexo II del
} RD. 
- Hay titulaciones de distintas materias de la misma área de conocimiento que no comparten ninguna de las asignaturas consideradas de formación básica, aunque sí pueden compartir materias.

De manera más concreta, la comparación de los cinco grados oficiales adscritos a la Facultad de Derecho de la Universidad de Barcelona (Ciencias Políticas y de la Administración, Criminología, Derecho, Gestión y Administración pública y Relaciones Laborales) confirma la descripción global efectuada para el área Ciencias Jurídicas y Sociales. En este sentido, todas las titulaciones optaron por configurar la formación básica con 60 créditos, en asignaturas de 6 créditos Y todas incluyeron una asignatura de carácter instrumental (Técnicas de trabajo y comunicación o Instrumentarium), que en las distintas Memorias ${ }^{37}$ se relacionaba con el área Comunicación. A su vez, todas parecen incluir una asignatura de corte humanístico, aparentemente adscribible al área de Historia, aunque formalmente no todas lo son (por ejemplo, Historia del Derecho, está adscrita al área Derecho). Por otra parte, el área Derecho proporciona asignaturas a los cinco Grados, pero limita para su Grado más directo (Derecho) la participación de otras materias distintas a Derecho a Ciencia Política, Economía y Comunicación. Los Grados con mayor número de materias (ocho) en su formación básica son Gestión y Administración Pública y Relaciones Laborales; por su parte, Ciencias Políticas y de la Administración y Criminología configuran con siete materias dicha formación. Y solo el Grado de Gestión y Administración Pública introdujo una asignatura (Tratamiento de la Información en la Administración Pública) de la materia Informática, adscrita a un área distinta (Ingeniería y Arquitectura) a la que se integra la titulación.

En el siguiente cuadro se aprecian gráficamente dichas conclusiones: ${ }^{38}$

\begin{tabular}{|l|l|l|l|l|}
\hline $\begin{array}{c}\text { CIENCIAS POLÍTICAS } \\
\text { Y DE LA } \\
\text { ADMINISTRACIÓN }\end{array}$ & CRIMINOLOGÍA & DERECHO & $\begin{array}{c}\text { GESTIÓN Y } \\
\text { ADMINISTRACIÓN } \\
\text { PÚBLICA }\end{array}$ & $\begin{array}{c}\text { RELACIONES } \\
\text { LABORALES }\end{array}$ \\
\hline Ciencia Política I & $\begin{array}{l}\text { Historia Política y Social } \\
\text { Contemporánea }\end{array}$ & Ciencia Política & $\begin{array}{l}\text { Historia Política y Social } \\
\text { Contemporánea }\end{array}$ & $\begin{array}{l}\text { Estadística Aplicada } \\
\text { a les Relaciones } \\
\text { Laborales }\end{array}$ \\
\hline
\end{tabular}

\footnotetext{
${ }^{37}$ Disponibles en https://www.ub.edu/portal/web/dret/verificacio-i-seguiment-graus

${ }^{38}$ Las asignaturas se colorean según la materia en que están adscritas, siguiendo la paleta de colores del cuadro incluido en el texto del área de conocimiento Ciencias Jurídicas y Sociales.
} 


\begin{tabular}{|c|c|c|c|c|}
\hline $\begin{array}{l}\text { Historia Política y Social } \\
\text { Contemporánea }\end{array}$ & $\begin{array}{l}\text { Introducción a la } \\
\text { Criminología }\end{array}$ & Derecho Romano & Introducción al Derecho & $\begin{array}{l}\text { Introducción a la } \\
\text { Economía }\end{array}$ \\
\hline Instrumentarium & $\begin{array}{l}\text { Introducción a la } \\
\text { Sociología }\end{array}$ & $\begin{array}{l}\text { Fundamentos del } \\
\text { Derecho }\end{array}$ & Sistema Político Espanyol & $\begin{array}{l}\text { Psicología del } \\
\text { Trabajo }\end{array}$ \\
\hline $\begin{array}{l}\text { Introducción al Derecho } \\
\text { Público }\end{array}$ & $\begin{array}{l}\text { Introducción al Derecho } \\
\text { Público }\end{array}$ & $\begin{array}{l}\text { Principios e } \\
\text { Instituciones } \\
\text { Constitucionales }\end{array}$ & Sociología & $\begin{array}{l}\text { Sistema Político i } \\
\text { Derecho } \\
\text { Constitucional }\end{array}$ \\
\hline Sociología General & $\begin{array}{l}\text { Técnicas de Trabajo y } \\
\text { Comunicación }\end{array}$ & $\begin{array}{l}\text { Técnicas de Trabajo y } \\
\text { Comunicación }\end{array}$ & $\begin{array}{l}\text { Técnicas de Trabajo y } \\
\text { Comunicación }\end{array}$ & $\begin{array}{l}\text { Técnicas de Trabajo } \\
\text { y Comunicación }\end{array}$ \\
\hline $\begin{array}{l}\text { Ciencias de la } \\
\text { Administración }\end{array}$ & Inglés Criminológico & $\begin{array}{l}\text { Derecho Civil de la } \\
\text { Persona }\end{array}$ & Derecho Constitucional & $\begin{array}{l}\text { Economía del } \\
\text { Trabajo }\end{array}$ \\
\hline Economía Política & $\begin{array}{l}\text { Derechos } \\
\text { Constitucionales y } \\
\text { Derechos Fundamentales }\end{array}$ & Economía & Economía Política & $\begin{array}{l}\text { Historia Económica y } \\
\text { Social }\end{array}$ \\
\hline Estructura Social & $\begin{array}{l}\text { Estadística y Análisis de } \\
\text { Datos }\end{array}$ & $\begin{array}{l}\text { Fundamentos del } \\
\text { Derecho Penal y } \\
\text { Teoría del Delito }\end{array}$ & $\begin{array}{l}\text { Tratamiento de la } \\
\text { Información en la } \\
\text { Administración Pública }\end{array}$ & $\begin{array}{l}\text { Introducción al } \\
\text { Derecho }\end{array}$ \\
\hline Sistema Político Español & $\begin{array}{l}\text { Introducción a la } \\
\text { Psicología }\end{array}$ & Historia del Derecho & $\begin{array}{l}\text { Estadística Aplicada en la } \\
\text { Administración Pública I }\end{array}$ & $\begin{array}{l}\text { Organización de } \\
\text { Empresas }\end{array}$ \\
\hline $\begin{array}{l}\text { Técnicas Estadísticas de } \\
\text { Investigación Social (TEIS) }\end{array}$ & $\begin{array}{l}\text { Introducción al Sistema } \\
\text { Político }\end{array}$ & $\begin{array}{l}\text { Organización } \\
\text { Territorial }\end{array}$ & $\begin{array}{l}\text { Estadística Aplicada en la } \\
\text { Administración Pública II }\end{array}$ & $\begin{array}{l}\text { Sociología del } \\
\text { Trabajo }\end{array}$ \\
\hline
\end{tabular}

Una última observación respecto del Grado de Derecho. Si comparamos las asignaturas de su formación básica con las que se incluían en la Licenciatura según el Plan de estudios de 1992, no hay diferencias significativas más allá de la asignatura de Grado Técnicas de investigación y comunicación. Como reconocía la propia Comisión Promotora "Nadie acusará de revolucionaria -si eso fuera una tacha- a la Propuesta elaborada [...]”39

39 Memoria Verifica, disponible en https://www.ub.edu/portal/documents/620105/1290961/DRET_memoria_verificada_alegacions.pdf/d95d $\underline{8379-d 107-484 \mathrm{e}-\mathrm{adba}-2 \mathrm{cf} 1 \mathrm{f} 55 \mathrm{a} \text { ccac }}$

Para un análisis general en las Universidades españolas, vid. BUENO SALINAS (2014) 125 y ss. 
Como ya se ha indicado, la última reforma universitario respecto de los itinerarios académicos de las diferentes titulaciones no fue aprovechada para introducir una real formación básica transversal, de corte humanístico, con la que incidir en la educación de ciudadanos libres. De haberlo sido, ello habría supuesto hacer efectiva la Declaración de la UNESCO de 1998 y avanzarse a lo que concreta, en la misma línea defendida por Nussbaum, la meta $7^{\text {a }}$ del objetivo 4 de los Objetivos de Desarrollo Sostenible - Agenda 2030: "asegurar que todos los alumnos adquieran los conocimientos teóricos y prácticos necesarios para promover el desarrollo sostenible, entre otras cosas mediante la educación para el desarrollo sostenible y los estilos de vida sostenibles, los derechos humanos, la igualdad de género, la promoción de una cultura de paz y no violencia, la ciudadanía mundial y la valoración de la diversidad cultural y la contribución de la cultura al desarrollo sostenible. ${ }^{40}$

En definitiva, todos los procesos educativos, desde el que se aborda en el ámbito familiar hasta el que culmina en las universidades, deberían abogar por formar ciudadanos libres, críticos, respetuosos y comprometidos con el otro, con el diferente. La salud de la democracia así lo requiere. Quienes como Nussbaum han dedicado su vida a la reflexión en este ámbito han dado la voz de alarma: "Sedientos de dinero, los estados nacionales y sus sistemas de educación están descartando sin advertirlo ciertas aptitudes que son necesarias para mantener viva a la democracia. Si esta tendencia se prolonga, las naciones de todo el mundo en breve producirán generaciones enteras de máquinas utilitarias, en lugar de ciudadanos cabales con la capacidad de pensar por sí mismos, poseer una mirada crítica sobre las tradiciones y comprender la importancia de los logros y los sufrimientos ajenos. El futuro de la democracia a escala mundial pende de un hilo." (NUSSBAUM, 2010, 20).

\section{A modo de epílogo}

La democracia liberal articulada vía el Estado de Derecho es (sigue siendo) indiscutiblemente atractiva. Y no solo porque -reafirmando la idea que en su día formulara Churchill- es el menos malo de los sistemas políticos conocidos en nuestra tradición socio-cultural, sino porque es un modo de vida. La democracia nos interpela y nos interesa a todos; nos hace partícipes de la configuración de las sociedades en las que vivimos y en el cómo vivimos en ellas. Ello no significa que no puedan ser revisables

\footnotetext{
${ }^{40}$ https://www.un.org/sustainabledevelopment/es/education/
} 
aspectos concretos que afectan a su ejercicio. El uso de las nuevas tecnologías, la rapidez de la información, el protagonismo del mercado, la amenaza de desaparecer desdibujados en la revolución digital ${ }^{41}$, entre otros muchos aspectos, están incidiendo de manera indiscutible en el espacio público, en lo político. Pero, los avances mencionados no siempre están repercutiendo de manera positiva. De manera paradójica, somos la sociedad que, con mayor y más fácil acceso a la información, está más desinformada. Los casos de corrupción, las fake news, los populismos, junto con la -en muchos casos- dolosa tergiversación del lenguaje, erosionan los fundamentos de las sociedades democráticas avanzadas. Y no ayuda nada el individualismo galopante, adiestrado por el Neoliberalismo que parece extenderse sin remedio.

La crisis de lo político, con seria amenaza a la democracia, no podemos atribuirla sin más a la falta de buenos políticos o de buenos partidos. Unos y otros forman también parte de las mismas sociedades que les cuestionan, acabando por erosionar la confianza de la ciudadanía en las instituciones. Por ello, en el fondo es la propia sociedad la que está en crisis ante el empuje del individualismo a ultranza.

Se habla de modernidad o sociedad líquida ${ }^{42}$ para hacer referencia a la cambiante y tambaleante época actual, percibida como muy alejada de cualquier garantía de estabilidad. Seguramente contribuye a ello la cada vez más preocupante ausencia de valores compartidos. Los valores sobre los que se erigieron las democracias liberales, los Estados sociales y democráticos de Derecho, se diluyen y se mutan en virus destructores. $\mathrm{Si}$ "la democracia empieza con la conversación", ${ }^{43}$ cuando la respuesta del otro es "mi concepto de democracia no es el mismo que el tuyo", la democracia está gravemente en riesgo porque el diálogo que la fundamenta es imposible. En los Estados sociales y democráticos de Derecho no hay, no debería haber tantos conceptos de democracia como individuos la conforman. Compartir valores pasa necesariamente por educar en los mismos. Del futuro de la democracia somos todos responsables.

\section{Bibliografía.}

\footnotetext{
${ }^{41}$ Vid. LASSALLE (2019) 19-20: "la institucionalidad de los gobiernos democráticos y la legitimidad de las sociedades abiertas de todo Occidente se encuentran en una profunda crisis de identidad. Se ven cuestionadas en sus fundamentos por la sustitución de la ciudadanía como presupuesto de la política democrática por múltiples digitales [...]".

${ }^{42}$ Expresión debida al sociólogo y filósofo Zygmunt Bauman (1925-2017).

${ }^{43}$ Afirmación del pedagogo y filósofo John Dewey (1859-1992).
} 
ARENDT, HANNAH. (1997). ¿Qué es política?, Barcelona, Ediciones Paidós.

Disponible en https://elartedepreguntar.files.wordpress.com/2009/06/arendt-hannahque-es-la-politica1.pdf

BUENO SALINAS, MARTA. (2014). “La enseñanza del Derecho en España”, en TURULL RUBINAT, MAX/ALBERTÍ ROVIRA, ENOCH (EDS.), La enseñanza del Derecho en Europa y América. Planes de estudio, metodologías, evaluación y acceso a las profesiones jurídicas, Barcelona, Octaedro-ICE.

CASTELLANOS CLARAMUNT, JORGE. (2019). "Educación y participación ciudadana: mejorar la docencia universitaria de la mano de los Derechos Humanos", en Revista de Educación y Derecho 19. Disponible en http://revistes.ub.edu/index.php/RED/index

CICERÓN. De Fato. Disponible en http://www.thelatinlibrary.com/cicero/fato.shtml\#1

FUKUYAMA, FRANCIS. (1990). “¿El fin de la Historia?”, en Claves de la Razón Práctica, 1. Disponible

en https://www.alianzaeditorial.es/minisites/manual_web/3491295/CAP8/1_FindelaHistori a.pdf

GINTIS H./VAN SCHAIK C./BOEHM C. (2015). “Zoon politikon: The evolutionary origins of human socio-political systems", en Behavioural Processes. Disponible en: http://sire.ub.edu/login?url=http://search.ebscohost.com/login.aspx?direct=true\&db=eds elc\&AN=edselc.2-52.0-85044918102\&lang=es\&site=eds-live

GUICHOT-REINA, VIRGINIA. (2015). "El «enfoque de las capacidades» de Martha Nussbaum y sus consecuencias educativas: hacia una pedagogía socrática y pluralista”, en Teoría de la educación 27/2. Disponible en http://revistas.usal.es/index.php/1130$\underline{3743 / \text { article/view/13799 }}$

HARARI, YUVAL NOAH. (2018). 21 lecciones para el siglo XXI, Barcelona, Penguin Random House Grupo Editorial.

HENRÍQUEZ R., ALFONSO. (2015). "La calidad de la educación universitaria, y su relación con la formación ciudadana", en Revista Pedagogía Universitaria y Didáctica 
del

derecho

$2 / 1$.

Disponible

en

https://pedagogiaderecho.uchile.cl/index.php/RPUD/issue/view/3798

HÖFFE, OTFRIED. (2007). Ciudadano económico, ciudadano del Estado, ciudadano del mundo. Ética política en la era de la globalización, Buenos Aires, Katz.

INNERARITY, DANIEL. (2017). "Democracy without Politics: Why Democracy Can Seriously Harm Democracy", en RedFame, Studies in Media and Communication 5/2.

JIMÉNEZ-DÍAZ, JOSÉ FRANCISCO (2017). "La ética política en Max Weber: contexto, análisis e interpretación”, en Perseitas 6/1.

JUDT, TONY. (2017). Algo va mal, Barcelona, Penguin Random House Group Editorial.

LASSALLE, José María. (2019). Ciberleviatán. El colapso de la democracia liberal frente a la revolución digital, Barcelona, Arpa.

LOIRA, J. MAXIMILIANO. (2017). "La crítica de A. MacIntyre al emotivismo contemporáneo", en Prometeica $15 . \quad$ Disponible en https://prometeica.com/ojs/index.php/prometeica/article/view/192

MACINTYRE, ALASDAIR. (1994). Justicia y racionalidad, Barcelona, Ediciones Internacionales Universitarias.

MACINTYRE, ALASDAIR. (2001). Tras la virtud, Barcelona, Biblioteca de Bolsillo. Disponible en https://circulosemiotico.files.wordpress.com/2012/10/tras-la-virtudmacintyre.pdf

MAGRIS, CLAUDIO. (2008). "Las fronteras del diálogo", en La historia no ha terminado. Ética, política, laicidad, Barcelona, Anagrama.

MANSUY HUERTA, DANIEL. (2015). Historia y política en el pensamiento de Friedrich Hayek. Una aproximación a Law, Legislation and Liberty, Santiago de Chile, Cuadernos de Empresa y Humanismo no 1. Disponible en http://www.ieschile.cl/wpcontent/uploads/2015/11/CUADERNO-EMPRESA-Y-HUMANISMO-FINAL.pdf

MARINA, JOSÉ ANTONIO/RAMBAUD, JAVIER. (2018). Biografía de la humanidad. Historia de la evolución de las culturas, Barcelona, Ariel. 
MARTÍNEZ MARTÍN, MIQUEL. (2006). "Formación para la ciudadanía y educación superior", en Revista Iberoamericana de Educación 42. Disponible en https://rieoei.org/historico/documentos/rie42a05.htm

MUÑOZ RAMÍREZ, ALICIA. (2016). “¿Qué ha sido de la Educación para la Ciudadanía con el Partido Popular?", en Foro de educación 14/20. Disponible en https://www.forodeeducacion.com/ojs/index.php/fde/article/view/429/330

NAVAL, CONCEPCIÓN/ARBUÉS, ELENA. (2016). “Citizenship Education Versus

Reality: The Facts in Spain”, en PETERSON, ANDREW/HATTAM, ROBERT/ZEMBYLAS, MICHALINOS/ARTHU, JAMES (Ed.), The Palgrave International Handbook of Education for Citizenship and Social Justice, London. Springer.

NUSSBAUM, MARTHA C. (2005). El cultivo de la humanidad. Una defensa clásica de la reforma en la educación liberal, Barcelona, Ediciones Paidós Ibérica.

NUSSBAUM, MARTHA C. (2010). Sin fines de lucro. Por qué la democracia necesita de las humanidades, Buenos Aires-Madrid, Katz Editores.

RECOMENDACIÓN [Rec (2002)12] del Comité de Ministros a los Estados miembros sobre la educación para la ciudadanía democrática adoptada por el Comité de Ministros el 16 de octubre de 2002, en la 812.a reunión de los Delegados de los Ministros. Disponible en https://www.fapar.org/documentos/Educacion_Ciudadania/Recomendaciones_E_Ciuda dania_EUROPA.pdf

SAIZ, MAURO JAVIER. (2015). "La comunidad para los comunitaristas: A. MacIntyre y C. Taylor", en Analecta política 5/9. Disponible en https://revistas.upb.edu.co/index.php/analecta/article/view/5024

SAN ISIDORO DE SEVILLA, (1982). Etimologías. Edición bilingüe, II. Biblioteca de Autores Cristianos, Madrid 1982.,

SAMPREDO, JOSÉ LUIS. (2011), “Debajo de la alfombra”, en ARTAL, R. Ma (coord.), Reacciona, Diez razones por las que debes actuar frente a la crisis económica, política y social, Madrid, Aguilar. 
UNESCO. (2006). Plan de acción para 2005-2007. Programa mundial para la educación en derechos humanos, Nueva York-Ginebra, 2006. Disponible en https://www.ohchr.org/Documents/Publications/PActionEducationsp.pdf

UNESCO. (2019). Strengthening the rule of law through education: a guide for policymakers. Disponible en https://unesdoc.unesco.org/ark:/48223/pf0000366771

URRUTIA LEÓN, MANUEL Mª (2016). “¿El mercado siempre tiene razón? Crítica de las ideas éticas, políticas y sociales del Neolibrealismo de F. Hayek", en Pensamiento 72.

WAPSHOTT, NICOLAS. (2017). Keynes vs Hayek. El choque que definió la economía moderna, Barcelona, Ediciones Deusto. 